\title{
Comparison of Oncostatin M Expression in Keratoacanthoma and Squamous Cell Carcinoma
}

\author{
Tien-Anh Tran, M.D., Jeffrey S. Ross, M.D., Christine E. Sheehan, B.S., J. Andrew Carlson, M.D. \\ Division of Dermatopathology, Department of Pathology and Laboratory Medicine, Albany Medical \\ College, Albany, New York
}

Oncostatin M (OSM) is a 28-kDa glycoprotein, produced by stimulated macrophages and $\mathrm{T}$ lymphocytes, that inhibits the proliferation and induces differentiation of a number of different cell lines derived from solid tumors. To determine whether keratoacanthoma (KA) is unique or a variant of squamous cell carcinoma (SCC), we compared the immunohistochemical expression of OSM in the tumor cells and peri- and intratumoral macrophages of 21 mature KAs, 7 regressing KAs, and 27 SCCs. An inverse correlation was identified between OSM tumor labeling and the density of OSM-labeled tumor-associated macrophages for KAs $(r=-.4$; $P=.09$ ). OSM tumor expression was significantly more frequent and more intense in KAs than in SCCs $(95 \%$ versus $63 \% ; P<.01)$. In contrast, the density of OSM-labeled macrophages was significantly higher in SCCs compared with mature KAs (7/3 high power fields versus $4 / 3$ high power fields; $P=.02)$. These OSM-positive macrophages were predominantly located at the advancing, infiltrative margins of both neoplasms. Regressing KAs demonstrated a decreased level of OSM tumor expression compared with mature KAs $(53 \%$ versus $95 \%$; $P=$ $.001)$, but there was no difference in density of OSMlabeled macrophages. Both the above differences and the overlapping patterns of OSM expression suggest that KAs are a variant of SCC where OSM, possibly as an autocrine factor, may mediate KA's overwhelming but not absolute tendency to involute.

KEY WORDS: Keratoacanthoma, Macrophages, Oncostatin M, Regression, Squamous cell carcinoma. Mod Pathol 2000;13(4):427-432

Copyright $(\mathcal{2} 2000$ by The United States and Canadian Academy of Pathology, Inc.

VOL. 13, NO. 4, P. 427, 2000 Printed in the U.S.A.

Date of acceptance: September 27, 1999.

Address reprint requests to: J. Andrew Carlson, M.D., Department of Pathology and Laboratory Medicine, Albany Medical College, MC-81, 47 New Scotland Avenue, Albany, NY 12208; e-mail: carlsoa@mail.amc.edu; fax: 518-252-6251.
Oncostatin M (OSM), produced by activated T lymphocytes and macrophages, initially was described in 1986 as a growth regulatory cytokine with an inhibitory activity on various solid tumor cell lines and a growth-stimulating effect on normal fibroblasts $(1,2)$. OSM belongs to the interleukin- 6 family, which includes interleukin-6, interleukin-11, ciliary neurotrophic factor, cardiotrophin-1, and leukemia inhibitory factor (3-6). Recently, OSM has been demonstrated to have a bifunctional activity: an antiproliferative effect on a variety of solid tumor cell lines, such as breast cancer $(7,8)$, melanoma (9), meningioma (10), and lung carcinoma (11), and a proliferative effect on cells from acquired immunodeficiency syndrome (AIDS)-related Kaposi's sarcoma $(12,13)$ and multiple myeloma $(14,15)$. The biologic effects of OSM in the pathogenesis of cutaneous epithelial tumors have not been explored.

Although first described more than 100 years ago by Hutchinson as a "crateriform ulcer of the face" (16), keratoacanthoma (KA) was actually popularized by Rook and Whimster in 1950 (17). The authors considered KA as a distinct and benign skin tumor characterized by a rapid growth phase followed invariably by self-involution within 4 to 6 mo. Although originally believed to be a benign lesion, rare cases of KA with aggressive behavior similar to squamous cell carcinoma (SCC) have been reported (18-25). Despite extensive literature concerning the relationship between KA and SCC, the issue of whether KA represents a unique entity or a variant of SCC has remained controversial (18, 26-31). In this study, we compared expression of OSM in mature and regressing KAs with conventional SCCs of the skin to determine whether KAs exhibit similarities or distinct differences that could explain KA's tendency to involute (regress).

\section{MATERIALS AND METHODS}

Twenty-eight SCCs, 21 mature KAs, and 8 regressing KAs were retrieved from the files of the dermatopathology department at the Albany Medical 
Center Hospital from a 3-mo period in 1998. All hematoxylin and eosin slides in each case were reviewed by two independent observers (TAT and JAC) using accepted histopathologic criteria for KA and $\operatorname{SCC}(1,2)$ to confirm the original histologic diagnosis. Specifically, (mature) KAs had to exhibit the following constellation of features: symmetric, well-defined cup-shaped contour, undermining of normal epidermis adjacent to a central orifice, glassy (pale staining) cytoplasm of central keratinocytes, atypia of peripheral keratinocytes, orthokeratotic cornified cells outnumbering parakeratotic ones, and horn microabscesses. Regressing KAs had to exhibit all of the following characteristics: roughly symmetric, cup-shaped neoplasm of atypical keratinocytes that undermine the epidermis adjacent to a central orifice, a central crater containing orthokeratotic cornified cells outnumbering parakeratotic ones, and a peripheral fibrotic stroma. SCCs could not have the previous two groupings of histologic characteristics. All of the original diagnoses were confirmed. Among the 21 mature KAs, 2 exhibited focal areas of regression. All SCCs were well-differentiated (20 cases) to moderately differentiated (7 cases), with 6 cases showing foci of large, glassy keratinocytes and 2 cases exhibiting focal acantholytic and adenoid differentiation (Fig. 1).

Formalin-fixed, paraffin-embedded 5 - $\mu$-thick sections from a representative block in each case were subjected to a mouse monoclonal antihuman antibody against OSM (1:10 dilution, clone 17001.31; Sigma, St. Louis, MO). Immunohistochemical staining was performed using the Ventana ES automated 3,3'-diaminobenzidine immunohistochemical system (Ventana Medical Systems, Tucson, AZ) with some modifications. The tissue was pretreated with enzyme digestion (Protease 1; Ventana) for $4 \mathrm{~min}$ and subsequently incubated for 32 min at $41^{\circ} \mathrm{C}$. To confirm the specificity of the primary antibodies, negative control slides were run with every batch using a mouse IgG2a isotype match (Sigma) at the same concentration as that of the primary antibodies.

Oncostatin immunoreactivity was limited to the cytoplasm. The extent of OSM immunopositivity in the tumor was graded as follows: 0, lesion completely negative or displayed only a weak staining; 1 , tumors showed a distinct moderate to strong cytoplasmic immunoreactivity. On scanning magnification, an obvious difference in the distribution of OSM-labeled macrophages was noted between KAs and SCCs. Specifically, KAs typically exhibited a scattered distribution of macrophages, and SCCs exhibited a clustered distribution in the peritumoral stroma. Therefore, to assess more rigorously the differences in OSM-labeled macrophages, we used the quantitative "hot spot" method previously
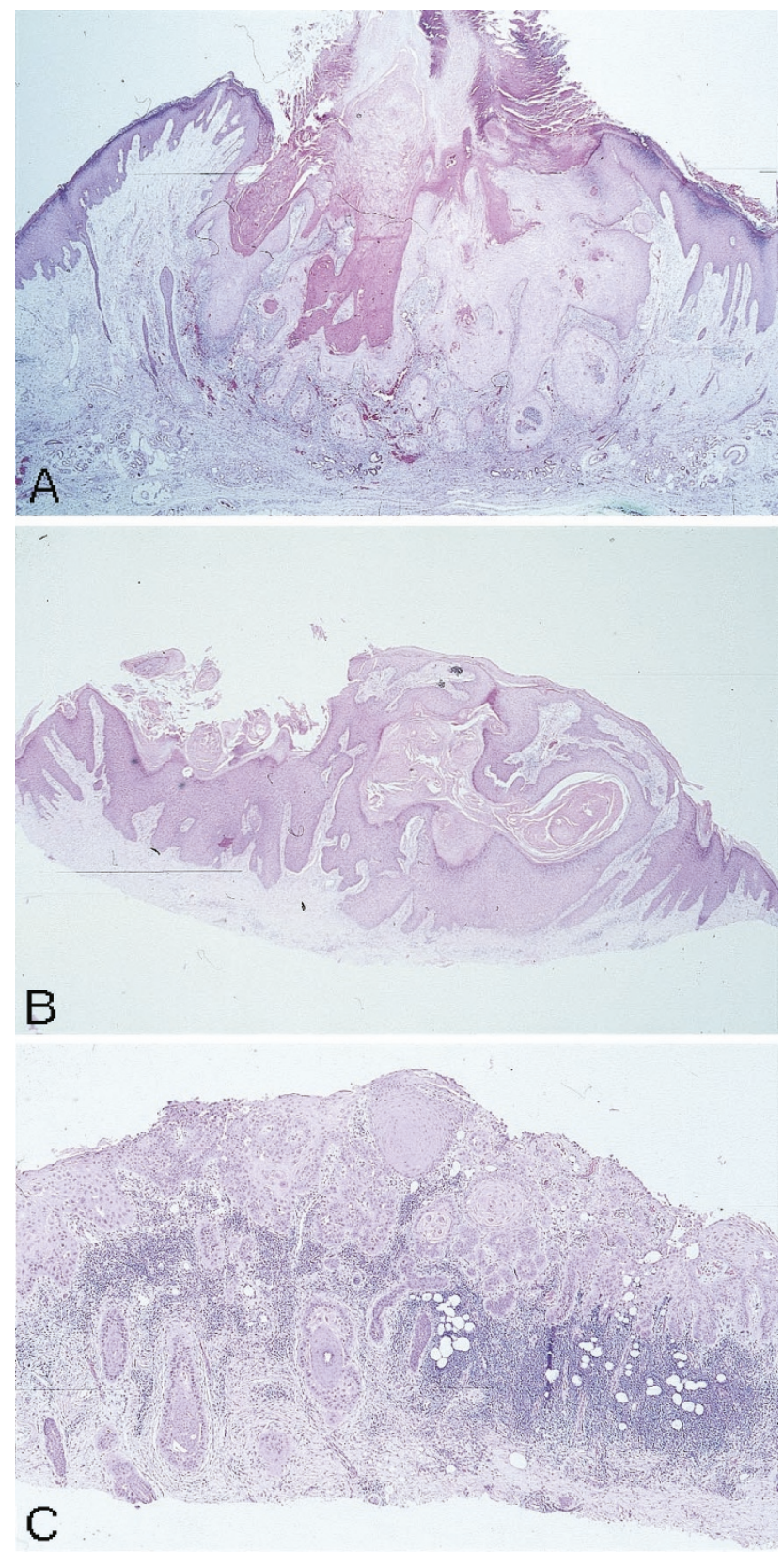

FIGURE 1. The diagnosis of keratoacanthoma is based on a constellation of histologic features, not on any one specific histologic characteristic. A constellation of histologic features, particularly in the clinical context of rapid growth and crateriform morphology, is diagnostic of keratoacanthoma. A, keratoacanthoma: symmetric, welldefined cup-shaped contour, undermining of normal epidermis adjacent to a central orifice, glassy (pale staining) cytoplasm of central keratinocytes, atypia of peripheral keratinocytes, orthokeratotic cornified cells outnumbering parakeratotic ones, and horn microabscesses. B, regressing keratoacanthoma: roughly symmetric cup-shaped neoplasm of atypical keratinocytes that undermine the epidermis adjacent to a central orifice, a central crater containing orthokeratotic cornified cells outnumbering parakeratotic ones, and a peripheral fibrotic stroma. C, conventional squamous cell carcinoma arising from a solar (actinic) keratosis: infiltrating cords and angulate nests of atypical keratinocytes infiltrating the dermis without all of the aforementioned features of keratoacanthomas.

described for evaluation of proliferative markers in KAs and SCCs $(32,33)$. Specifically, under lowpower magnification $(\times 100)$, the entire tissue sec- 
tions were examined and the area of highest density of OSM-positive macrophages around or within the tumor was noted (hot spot area). The hot spot area was subsequently scrutinized under high power $(\times 400)$, and the number of OSM-positive macrophages within 3 high-power fields was determined.

Statistical comparisons were carried out with the STATA software (College Station, TX) using the $\chi^{2}$ test for dichotomous variables, the $t$ test for continuous variables, and analysis of pairwise covariance for relationships between variables. The criterion for significance was $P<.05$.

\section{RESULTS}

Most KAs showed tumor cell cytoplasmic OSM immunoreactivity, whereas a significantly lesser proportion of SCCs did (Table 1). In contrast to the relatively moderate staining intensity of the tumor cells to OSM, the intra- and perilesional macrophages featured a dark, intense cytoplasmic staining. By scanning magnification, most KAs (71\%) had a sparse, scattered infiltrate of OSM-labeled macrophages, whereas most SCCs (70\%) had dense clusters of OSM-positive macrophages $(P=.004)$. These OSM-positive macrophages typically were located in the surrounding stroma at the advancing, infiltrative borders of the tumors (Fig. 2). An inverse correlation was identified between neoplastic keratinocyte labeling and the presence of increasing numbers of tumor-associated OSM-labeled macrophages for KAs $(r=-.4 ; P=.09$, analysis of pairwise covariance). However, this trend was not found for either SCCs $(r=.02 ; P=.9)$ or regressing KAs $(r=.4 ; P=.4)$. In addition, the adjacent epidermis, in some cases, showed faint keratinocyte immunoreactivity that was much less intense than the KAs and SCCs that were graded as positive. The epithelium in the normal tonsillar controls did not label with OSM.

Histologically, regressing KAs were characterized by a shallow crateriform proliferation of squamous epithelium with a central keratin plug, flattened peripheries, and associated inflammatory and fibrotic changes in the surrounding dermis. In contrast to mature KAs, approximately half of regressing KAs showed immunoreactivity to OSM. However, the number of OSM-labeled macro-

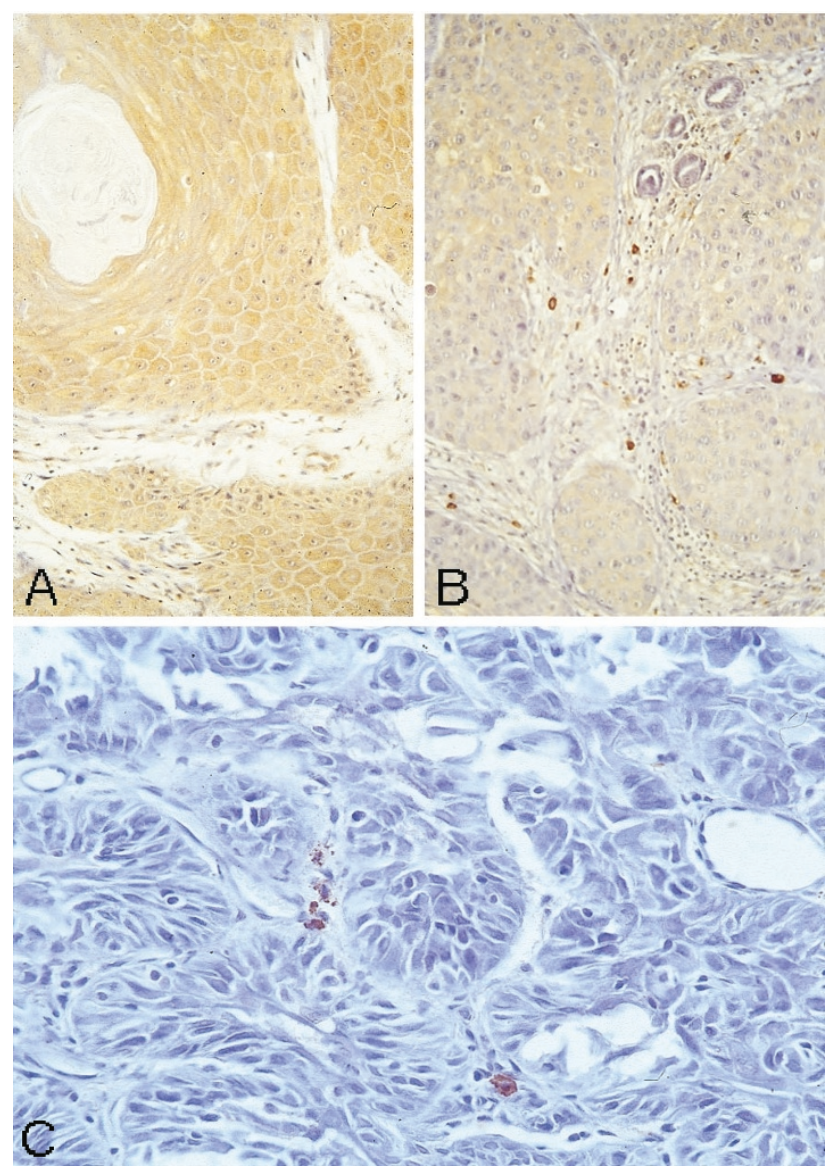

FIGURE 2. Dual expression (tumor cells and macrophages) of oncostatin M (OSM) in cutaneous squamous neoplasms. A, keratoacanthoma (KA) showing moderately intense cytoplasmic OSM immunoreactivity. Note the absence of OSM-positive macrophages in this field of the KA. B, squamous cell carcinomas exhibit a higher mean level of tumor-associated OSM-labeled macrophages and less frequent and faint OSM labeling of tumor cells as compared with KA. C, another example of a squamous cell carcinoma with no tumor labeling and numerous peritumoral macrophages.

phages in regressing KAs was similar to that of mature KAs and significantly lower than SCCs.

\section{DISCUSSION}

The histopathologic features of KA have been extensively studied and well-described. A constellation of morphologic features are diagnostic of KAs and consist of the following: symmetric, welldefined cup-shaped contour, undermining of normal epidermis adjacent to a central orifice, glassy

TABLE 1. Comparison of Oncostatin M in Squamous Cell Carcinoma, Keratoacanthoma, and Regressing Keratoacanthoma

\begin{tabular}{|c|c|c|c|c|}
\hline & $\begin{array}{l}\text { Squamous Cell } \\
\text { Carcinoma }\end{array}$ & Keratoacanthoma & $\begin{array}{c}\text { Regressing } \\
\text { Keratoacanthoma }\end{array}$ & $P$ Values $^{a}$ \\
\hline OSM tumor labeling & $17 / 27(63 \%)$ & $20 / 21(95 \%)$ & $4 / 7(53 \%)$ & $0.001 / 0.001$ \\
\hline $\begin{array}{l}\text { OSM macrophage labeling } \\
\text { (range) }\end{array}$ & 7/3 HPF (1-20/3 HPF) & 4/3 HPF (1- 20/3 HPF) & 3/3 HPF (1- 12/3 HPF) & $0.01 / \mathrm{NS}$ \\
\hline
\end{tabular}

${ }^{a} P$ values determined by $\chi^{2}$ test or $t$ test with significance set at $P<.05$; first value represents comparison of squamous cell carcinomas with keratoacanthomas; second value represents comparison of keratoacanthomas with regressing keratoacanthomas. 
(pale staining) cytoplasm of central keratinocytes, atypia of peripheral keratinocytes, orthokeratotic cornified cells outnumbering parakeratotic ones, and horn microabscesses $(1,2)$. However, none of these individual histologic characteristics is pathognomonic for KA as each, individually, can be found in some cases of SCC. Given the rapid growth and self-involuting tendency of KA, examining for factors involved, such as a growth regulatory cytokine like OSM, likely would represent a promising technique to distinguish KAs from conventional SCCs.

The mechanisms involved in the involution of KA have not been completely elucidated. The frequent presence of inflammatory cell infiltrates associated with KAs suggests a role for an immunologic host response in confining local growth, preventing distant metastasis, and inducing regression. Supporting this supposition are numerous studies demonstrating an increase of activated intratumoral CD4positive $\mathrm{T}$ cells $(34,35)$, fewer numbers of eosinophils (36), and increased Langerhans' cells (37) in KA compared with SCC, and a high incidence of KAs in patients who experience immunosuppression $(20,38,39)$. In addition, KAs can exhibit expression of human leukocyte antigen DR (40). Despite these findings in support of immunologically mediated regression, nonimmunologic mechanisms have been postulated (41) and by chromosomal analysis, KAs seem to be distinct from SCCs de novo (42). Nonetheless, the potential role of tissue macrophages participating in the immune host response to these cutaneous neoplasms has not been extensively studied (43).

Increased numbers of Langerhans' cells $(44,45)$ can be identified at the infiltrative margins of squamous neoplasms and are suspected to be "related to the invasive process which is localized to focal areas at the periphery of infiltrating tumors" (46). The highest density of OSM-labeled macrophages in this study was observed at the infiltrating margins of both KAs and SCCs. SCCs exhibited significantly higher mean levels of these macrophages than did KAs. This host OSM-positive macrophage response could be related to tumor aggressiveness similar to that reported for malignant melanomas (47). In support of this theory, we found an inverse correlation between the OSM-labeled tumor cells and tumor-associated OSM-labeled macrophages for KAs. This inverse pattern of OSM expression likely reflects the reported differences between largely clinically benign KAs (OSM-positive and low levels of OSM macrophages) and potentially clinically aggressive SCCs (OSM-negative with high levels of OSM macrophages). This indirect relationship may represent a negative feedback mechanism between the tumor cells and the surrounding infiltrative macrophages. OSM-labeled tumor cells could illicit a negative signal to the secreting macrophages, resulting in reduction of OSM synthesis and the smaller number of OSM-labeled macrophages identified in this study.

Both KAs and, to a lesser extent, SCCs expressed OSM. This finding may be attributable to endogenous synthesis of OSM by the tumor cells-an autocrine effect-or represent a bound form of OSM (OSM and receptor) - a paracrine effect. Although OSM is predominantly produced by activated $\mathrm{T}$ lymphocytes and macrophages, the possibility that these squamous neoplasms produce OSM is supported by reports of OSM synthesis in meningiomas (10), AIDS-related Kaposi's sarcoma $(12,13)$, and the epidermis overlying AIDS-related Kaposi's sarcoma (13). Nonetheless, the relatively weaker immunointensity of tumor cells compared with that of macrophages does not discount a paracrine phenomenon of nontumoral OSM bound to its receptor(s). OSM mediates its effects via two distinct receptor complexes (48): type 1 OSM receptor, which is also shared with the leukemia inhibitory factor (49), and type 2 OSM receptor, which is specific for OSM (5). Both types of OSM receptors have been described in malignant and benign mammary cell lines. Downregulation of OSM-specific receptors (type 2) in breast cancer cells compared with benign mammary cells (5) and upregulation of OSM-specific receptors of some breast cancer cell lines both have been reported to be responsible for OSM's antiproliferative function (7). Therefore, it is conceivable that downregulation of OSM-specific receptors in SCC or upregulation of these receptors in KA may result in the differences between these two neoplasms with respect to both OSM immunoreactivity and clinical behavior.

OSM can induce differentiation in breast cancer (7) and leukemic cells (50). The significantly lower prevalence of OSM labeling in regressed KAs compared with mature KAs may reflect this cytokine function and the presence of mature (fully differentiated) keratinocytes in regressed KAs. Most studies of the squamous immunophenotype of KAs demonstrate a higher degree of differentiation in KAs compared with SCCs (51-56). Moreover, the presence of a fibrotic reaction at the interface of regressing KA and the surrounding stroma may be a reflection of the ability of OSM to affect fibroblasts $(6,9,57)$.

The overlap of OSM expression for both tumor labeling and associated macrophages indicates that OSM is not a specific marker that is useful for distinction of KAs from conventional SCCs. However, the significant differences of higher frequency of OSM tumor labeling and lower mean levels of OSM-labeled macrophages identified in KAs suggest that OSM plays a role in the evolution of keratoacanthomas, possibly as an autocrine factor that 
decreases proliferation and induces differentiation resulting in KA's reported overwhelming tendency to involute.

\section{REFERENCES}

1. Weedon D. Tumors of the epidermis. In: Weedon D, editor. Skin pathology. Edinburgh: Churchill Livingstone; 1997. pp. 635-71.

2. Kern WH, McCray MK. The histopathologic differentiation of keratoacanthoma and squamous cell carcinoma of the skin. J Cutan Pathol 1980;7(5):318-25.

3. Miyajima A, Hara T, Kitamura T. Common subunits of cytokine receptors and the functional redundancy of cytokines. Trends Biochem Sci 1992;17(10):378-82.

4. Kishimoto T, Akira S, Narazaki M, Taga T. Interleukin-6 family of cytokines and gp130. Blood 1995;86(4):1243-54.

5. Liu J, Hadjokas N, Mosley B, Estrov Z, Spence MJ, Vestal RE. Oncostatin $\mathrm{M}$-specific receptor expression and function in regulating cell proliferation of normal and malignant mammary epithelial cells. Cytokine 1998;10(4):295-302.

6. Richards CD, Langdon C, Botelho F, Brown TJ, Agro A. Oncostatin $M$ inhibits IL-1-induced expression of IL-8 and granulocyte-macrophage colony-stimulating factor by synovial and lung fibroblasts. J Immunol 1996;156(1):343-9.

7. Douglas AM, Grant SL, Goss GA, Clouston DR, Sutherland RL, Begley CG. Oncostatin M induces the differentiation of breast cancer cells. Int J Cancer 1998;75(1):64-73.

8. Douglas AM, Goss GA, Sutherland RL, Hilton DJ, Berndt MC, Nicola NA, et al. Expression and function of members of the cytokine receptor superfamily on breast cancer cells. Oncogene 1997;14(6):661-9.

9. Brown TJ, Lioubin MN, Marquardt H. Purification and characterization of cytostatic lymphokines produced by activated human $\mathrm{T}$ lymphocytes: synergistic antiproliferative activity of transforming growth factor beta 1, interferongamma, and oncostatin $\mathrm{M}$ for human melanoma cells. J Immunol 1987;139(9):2977-83.

10. Schrell UM, Koch HU, Marschalek R, Schrauzer T, Anders M, Adams E, et al. Formation of autocrine loops in human cerebral meningioma tissue by leukemia inhibitor factor, interleukin-6, and oncostatin M: inhibition of meningioma cell growth in vitro by recombinant oncostatin M. J Neurosurg 1998;88(3):541-8.

11. Horn D, Fitzpatrick W, Gomper P, Ochs V, Bolton-Hansen $\mathrm{M}$, Zarling J, et al. Regulation of cell growth by recombinant oncostatin M. Growth Factors 1990;2:157-65.

12. Nair BC, DeVico AL, Nakamura S, Copeland TD, Chen Y, Patel A, et al. Identification of a major growth factor for AIDS-Kaposi's sarcoma cells as oncostatin M. Science 1992; 255(5050):1430-2.

13. Cai J, Gill PS, Masood R, Chandrasoma P, Jung B, Law RE, et al. Oncostatin-M is an autocrine growth factor in Kaposi's sarcoma. Am J Pathol 1994;145(1):74-9.

14. Zhang XG, Gu JJ, Lu ZY, Yasukawa K, Yancopoulos GD, Turner K, et al. Ciliary neurotropic factor, interleukin 11, leukemia inhibitory factor, and oncostatin $\mathrm{M}$ are growth factors for human myeloma cell lines using the interleukin 6 signal transducer gp130. J Exp Med 1994;179(4):1337-42.

15. Westendorf JJ, Jelinek DF. Growth regulatory pathways in myeloma: evidence for autocrine oncostatin M expression. J Immunol 1996;157(7):3081-8.

16. Hutchinson J. the crateriform ulcer of the face: a form of epithelial cancer. Trans Pathol Soc London 1889;40:275-81.

17. Rook A, Whimster I. Le keratoacanthome. Arch Belg Dermatol Syphilol 1950;6:137-46.

18. Hodak E, Jones RE, Ackerman AB. Solitary keratoacanthoma is a squamous-cell carcinoma: three examples with metas- tases [see comments]. Am J Dermatopathol 1993;15(4):33242; discussion 343-52.

19. Piscioli F, Boi S, Zumiani G, Cristofolini M. A gigantic, metastasizing keratoacanthoma: report of a case and discussion on classification. Am J Dermatopathol 1984;6(2):123-9.

20. Poleksic S. Keratoacanthoma and multiple carcinomas. Br J Dermatol 1974;91(4):461-3.

21. Schnur PL, Bozzo P. Metastasizing keratoacanthomas? The difficulties in differentiating keratoacanthomas from squamous cell carcinomas. Plast Reconstr Surg 1978;62(2):258-62.

22. Kingman J, Callen JP. Keratoacanthoma: a clinical study. Arch Dermatol 1984;120(6):736-40.

23. Lapins NA, Helwig EB. Perineural invasion by keratoacanthoma. Arch Dermatol 1980;116(7):791-3.

24. Janecka IP, Wolff M, Crikelair GF, Cosman B. Aggressive histological features of keratoacanthoma. J Cutan Pathol 1977;4(6):342-8.

25. Calonje E, Jones EW. Intravascular spread of keratoacanthoma: an alarming but benign phenomenon. Am J Dermatopathol 1992;14(5):414-7.

26. LeBoit PE. Is keratoacanthoma a variant of squamous cell carcinoma. New insights into an old controversy ... soon? Am J Dermatopathol 1995;17(4):319-20.

27. Manstein $\mathrm{CH}$, Frauenhoffer CJ, Besden JE. Keratoacanthoma: is it a real entity? Ann Plast Surg 1998;40(5):469-72.

28. Sanders GH, Miller TA. Are keratoacanthomas really squamous cell carcinomas? Ann Plast Surg 1982;9(4):306-9.

29. Bowman H, Pinkus H. Keratoacanthoma (Molluscum sebaceum). Arch Pathol 1955;48:19-25.

30. Connors RC, Ackerman AB. Histologic pseudomalignancies of the skin. Arch Dermatol 1976;112(12):1767-80.

31. Reed RJ. Actinic keratoacanthoma. Arch Dermatol 1972;106(6):858-64.

32. Kerschmann RL, McCalmont TH, LeBoit PE. p53 oncoprotein expression and proliferation index in keratoacanthoma and squamous cell carcinoma. Arch Dermatol 1994;130(2): 181-6.

33. Tran TA, Ross JS, Carlson JA, Mihm MC Jr. Mitotic cyclins and cyclin-dependent kinases in melanocytic lesions. Hum Pathol 1998;29(10):1085-90.

34. Patel A, Halliday GM, Cooke BE, Barnetson RS. Evidence that regression in keratoacanthoma is immunologically mediated: a comparison with squamous cell carcinoma. Br J Dermatol 1994;131(6):789-98.

35. Halliday GM, Patel A, Hunt MJ, Tefany FJ, Barnetson RS. Spontaneous regression of human melanoma/nonmelanoma skin cancer: association with infiltrating CD4+ T cells. World J Surg 1995;19(3):352-8.

36. Lowe D, Fletcher CD, Shaw MP, McKee PH. Eosinophil infiltration in keratoacanthoma and squamous cell carcinoma of the skin. Histopathology 1984;8(4):619-25.

37. Korenberg R, Penneys NS, Kowalczyk A, Nadji M. Quantitation of S100 protein-positive cells in inflamed and noninflamed keratoacanthoma and squamous cell carcinoma. J Cutan Pathol 1988;15(2):104-8.

38. Cohen EB, Komorowski RA, Clowry LJ. Cutaneous complications in renal transplant recipients. Am J Clin Pathol 1987; 88(1):32-7.

39. Jensen P, Clausen OP, Geiran O, Simonsen S, Relbo A, Hansen $\mathrm{S}$, et al. Cutaneous complications in heart transplant recipients in Norway 1983-1993. Acta Derm Venereol 1995; 75(5):400-3.

40. Markey AC, Churchill LJ, MacDonald DM. Altered expression of major histocompatibility complex (MHC) antigens by epidermal tumours. J Cutan Pathol 1990;17(2):65-71.

41. Stone O. Non-immunologic enhancement and regression of self-healing squamous cell carcinoma (keratoacanthoma)ground substance and inflammation. Med Hypothesis 1988; 26:113-7. 
42. Waring AJ, Takata M, Rehman I, Rees JL. Loss of heterozygosity analysis of keratoacanthoma reveals multiple differences from cutaneous squamous cell carcinoma. Br J Cancer 1996;73(5):649-53.

43. Dammacco F, Miglietta A, Lospalluti M, Meneghini C, Bonomo L. Macrophages in skin cancer: quantitative and functional studies. Tumori 1979;65(3):309-16.

44. Phillips P, Helm KF. Proliferating cell nuclear antigen distribution in keratoacanthoma and squamous cell carcinoma. J Cutan Pathol 1993;20(5):424-8.

45. Fernandez-Bussy R, Cambazard F, Mauduit G, Schmitt D, Thivolet J. T cell subsets and Langerhans cells in skin tumours. Eur J Cancer Clin Oncol 1983;19(7):907-13.

46. McArdle JP, Knight BA, Halliday GM, Muller HK, Rowden G. Quantitative assessment of Langerhans cells in actinic keratosis, Bowen's disease, keratoacanthoma, squamous cell carcinoma and basal cell carcinoma. Pathology 1986;18(2): 212-6.

47. Brocker EB, Zwadlo G, Suter L, Brune M, Sorg C. Infiltration of primary and metastatic melanomas with macrophages of the 25F9-positive phenotype. Cancer Immunol Immunother 1987;25(2):81-6.

48. Thoma B, Bird TA, Friend DJ, Gearing DP, Dower SK. Oncostatin $\mathrm{M}$ and leukemia inhibitory factor trigger overlapping and different signals through partially shared receptor complexes. J Biol Chem 1994;269(8):6215-22.

49. Gearing DP, Comeau MR, Friend DJ, Gimpel SD, Thut CJ, McGourty J, et al. The IL-6 signal transducer, gp130: an oncostatin $M$ receptor and affinity converter for the LIF receptor. Science 1992;255(5050):1434-7.

50. Bruce AG, Hoggatt IH, Rose TM. Oncostatin M is a differen- tiation factor for myeloid leukemia cells. J Immunol 1992; 149(4):1271-5.

51. Seelentag WK, Gunthert U, Saremaslani P, Futo E, Pfaltz M, Heitz PU, et al. CD44 standard and variant isoform expression in human epidermal skin tumors is not correlated with tumor aggressiveness but down-regulated during proliferation and tumor de-differentiation. Int J Cancer 1996;69(3): 218-24.

52. Krunic AL, Garrod DR, Madani S, Buchanan MD, Clark RE. Immunohistochemical staining for desmogleins 1 and 2 in keratinocytic neoplasms with squamous phenotype: actinic keratosis, keratoacanthoma and squamous cell carcinoma of the skin. Br J Cancer 1998;77(8):1275-9.

53. Smoller BR, Kwan TH, Said JW, Banks-Schlegel S. Keratoacanthoma and squamous cell carcinoma of the skin: immunohistochemical localization of involucrin and keratin proteins. J Am Acad Dermatol 1986;14(2 Pt 1):226-34.

54. Kannon G, Park HK. Utility of peanut agglutinin (PNA) in the diagnosis of squamous cell carcinoma and keratoacanthoma. Am J Dermatopathol 1990;12(1):31-6.

55. Ho T, Horn T, Finzi E. Transforming growth factor alpha expression helps to distinguish keratoacanthomas from squamous cell carcinomas. Arch Dermatol 1991;127(8):1167-71.

56. Jensen $P$, Clausen $P$, Bryne M. Differences in sialyl-Tn antigen expression between keratoacanthomas and cutaneous squamous cell carcinomas. J Cutan Pathol 1999;26:183-9.

57. Zarling JM, Shoyab M, Marquardt H, Hanson MB, Lioubin MN, Todaro GJ. Oncostatin M: a growth regulator produced by differentiated histiocytic lymphoma cells. Proc Natl Acad Sci U S A 1986;83(24):9739-43. 